\title{
ESTUDO DA INFLUÊNCIA DO MÉTODO DE SECAGEM NA MICROESTRUTURA E PROPRIEDADES DE TEXTURA DE BANANA (VAR.PRATA)
}

\author{
B.D.A. PORCIUNCULA ${ }^{1}$, J. B. LAURINDO ${ }^{1}$ \\ ${ }^{1}$ Universidade Federal de Santa Catarina, Departamento de Engenharia Química e Engenharia de \\ Alimentos \\ E-mail para contato: barbara.porciuncula@gmail.com
}

\begin{abstract}
RESUMO - O objetivo desse trabalho foi investigar o efeito do método de secagem sobre a porosidade, encolhimento, textura e microestrutura de fatias de banana. As amostras foram desidratadas por conductive multi-flash drying (KMFD), por conductive multi-flash drying seguido por um período de secagem a vácuo (KMFD_VD), secagem convectiva com ar quente (SC) e secagem a vácuo (SV). Nas técnicas de secagem por KMFD e KMFD_VD as amostras foram aquecidas à pressão atmosférica até $60{ }^{\circ} \mathrm{C}$, quando foi aplicado um pulso de vácuo (5 minutos) na câmara que atingiu a pressão final de $1500 \mathrm{~Pa}$. No KMFD as amostras foram submetidas à 12 ciclos de aquecimento-pulso de vácuo, no processo KMFD_VD as amostras foram submetidas a 3 ciclos de aquecimento-pulso de vácuo, seguidos da secagem a vácuo. As amostras secas por SC apresentaram um maior encolhimento $(70 \%)$ e menor porosidade $(56 \%)$. As amostras submetidas às técnicas de KMFD e KMFD_VD apresentaram alta porosidade, $75 \%$ e $87 \%$, respectivamente e textura crocante.
\end{abstract}

\section{INTRODUÇÃO}

As propriedades estruturais dos alimentos, tais como densidade aparente, densidade real e porosidade são significativamente afetadas pelo método de secagem e variáveis de processo utilizadas. O conhecimento de como o processo de secagem influencia a microestrutura e textura dos alimentos na desidratação é importante, pois estas propriedades definem uma parte da qualidade dos produtos obtidos.

Tradicionalmente, secagem convectiva, secagem a vácuo e liofilização, além da desidratação osmótica, como método de pré-desidratação, são as técnicas de secagem mais comumente utilizadas. Durante a secagem, a retirada da umidade afeta fortemente as propriedades de textura do produto, devido ao encolhimento da estrutura. Materiais secos pelo método convectivo são caracterizados por possuírem baixa porosidade e alta densidade aparente (Zogzas et al., 1994; Ramírez et al., 2012). A técnica de liofilização produz alimentos secos com baixa densidade aparente, devido à alta porosidade resultante. Além disso, a estrutura, cor e aroma do produto são preservados. Entretanto, essa técnica possui a desvantagem de ser dispendiosa e exigir longos períodos de secagem (Krokida e Maroulis, 1998). 


\section{9 a 22 de outubro de 2014 \\ Florianópolis/SC}

Por outro lado, processos de secagem que utilizam ciclos de aquecimento-pulso de vácuo produzem frutas com textura crocante, semelhante às obtidas pelo processo de liofilização. Essa classe de processo baseia-se na aplicação de sucessivos ciclos de aquecimento-pulso de vácuo a frutas e hortaliças, até que a umidade final desejada seja alcançada (Laurindo et al., 2011; Zotarelli et al., 2012).

O objetivo deste trabalho foi analisar a influência do método de secagem na formação e no comportamento da microestrutura de bananas (var. Prata). As técnicas de secagem analisadas foram: secagem por conductive multi-flash drying (KMFD), conductive multi-flash drying seguida de um período de secagem a vácuo (KMFD_VD), secagem convectiva (CD) e secagem a vácuo clássica (VD). As mudanças microestruturais ocorridas durante os processos de secagem estudados foram analisadas através de micrografias eletrônicas de varredura e correlacionadas com a densidade aparente, porosidade e encolhimento das amostras.

\section{MATERIAL E MÉTODOS}

Amostras de banana (Musa sapientum L., var Prata) foram adquiridas no comércio local (Florianópolis, SC, Brasil). A seleção das amostras foi realizada pela aparência e através do grau de maturação, foram avaliados o conteúdo de sólidos solúveis (utilizando um refratômetro ótico manual, AR200 Reichert, EUA) e a resistência à penetração (utilizando um penetrômetro, Effegi Mod FT 327, $\varnothing=8 \mathrm{~mm}$, Itália). As amostras selecionadas foram lavadas, descascadas manualmente $\mathrm{e}$ posteriormente cortadas em fatias de $5 \mathrm{~mm}$ de espessura.

Após o preparo, as amostras de banana foram submetidas à secagem. Diferentes técnicas de secagem foram utilizadas: Conductive multi-flash drying (KMFD), Conductive multi-flash drying seguida de um período de secagem a vácuo (KMFD_VD), secagem convectiva (CD) e secagem a vácuo clássica (VD).

A Figura 1 representa o diagrama esquemático do dispositivo experimental utilizado para a secagem por Conductive multi-flash drying (KMFD) e por Conductive multi-flash drying seguida de um período de secagem a vácuo (KMFD_VD). O aparato experimental consiste numa câmara de secagem de 100L (440-DE, Ethik Technology, Brasil) conectada a uma bomba de vácuo com capacidade de bombeamento de $350 \mathrm{~m}^{3} / \mathrm{h}$ (LC305-DVP Vacuum Technology, Itália). Um sistema de condensação (trapping) foi instalado na linha. No interior da câmara de secagem, as placas de acondicionamento das amostras foram mantidas aquecidas a $80^{\circ} \mathrm{C}$ por resistências elétricas. Após a preparação das amostras, as mesmas foram dispostas em folhas de mylar® e colocadas no interior da câmara de secagem sobre as placas aquecidas. O aquecimento das amostras foi realizado à pressão atmosférica. Atingido $60^{\circ} \mathrm{C}$ no interior das frutas, o sistema era evacuado pela aplicação de um pulso de vácuo. Transcorridos 5 minutos de evacuação a pressão do sistema era reestabelecida e um novo ciclo de aquecimento-pulso de vácuo aplicado. A pressão do sistema foi monitorada durante a secagem através de um vacuômetro digital (Multi-Range Vacuum Gauge PIZA 111 - ILMVAC, Alemanha). A variação da temperatura das amostras durante a secagem foi monitorada utilizando termopares do tipo T (Iope, model A-TX-TF-TF-R30AWG, Brasil), inseridos em cinco amostras em diferentes locais do secador, e conectados a um sistema de aquisição de dados (34970A, Agilent 
Technologies, EUA). Os termopares foram conectados hermeticamente à estufa através de um flange (Kaye feed thru, General Eletric- EUA).

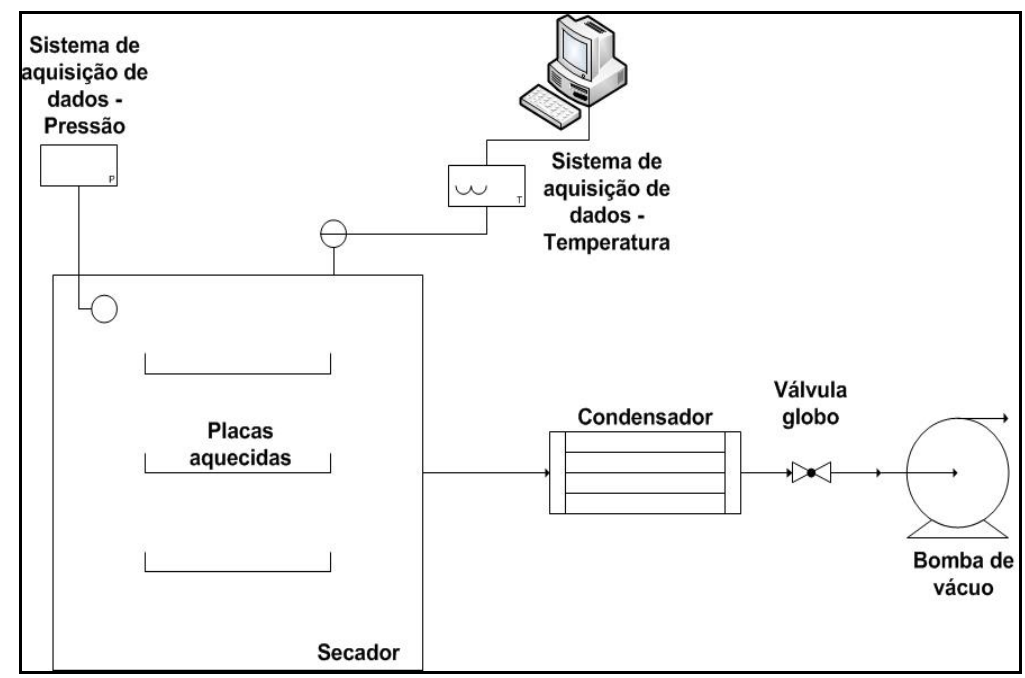

Figura 1 - Diagrama esquemático do dispositivo experimental utilizado para a secagem por Conductive multi-flash drying (KMFD) e por Conductive multi-flash drying seguida de um período de secagem a vácuo (KMFD_VD).

Na secagem por KMFD_VD foram aplicados 3 ciclos de aquecimento-pulsos de vácuo seguidos por uma secagem à vácuo $(65 \mathrm{~min})$, totalizando um tempo de secagem de 2 horas.

A secagem convectiva foi realizada em estufa (TE394/2, TECNAL, Brasil) a $60^{\circ} \mathrm{C}$, umidade relativa no interior do equipamento de $12 \%$ e velocidade do ar de $1 \mathrm{~m} / \mathrm{s}$. A secagem a vácuo clássica foi realizada em estufa (440-DE, Ethick Technology, Brasil) a $60{ }^{\circ} \mathrm{C}$ e pressão de $15 \mathrm{kPa}$.

O volume real $\left(V_{t}\right)$ foi medido usando um picnômetro de gás, construído para trabalhar com sólidos úmidos ou secos, de acordo com metodologia proposta por Sereno et al. (2007). O volume aparente $\left(V_{b}\right)$ foi determinado pelo deslocamento de volume das amostras quando imersas em nheptano (Lozano et al., 1980). A porosidade foi calculada a partir do volume real $\left(V_{t}\right)$ e do volume aparente $\left(V_{b}\right)$, usando a Equação 1.

O encolhimento das amostras foi determinado pela relação entre o volume aparente da amostra num determinado tempo pelo volume aparente inicial $(\mathrm{t}=0)$ segundo a Equação 2.

$$
\varepsilon[\%]=\left[1-\frac{V_{t}}{V_{b}}\right] \times 100
$$




$$
S_{b}[\%]=\left[1-\frac{V_{b}}{V_{b 0}}\right] \times 100
$$

Os teores de umidade das amostras foram determinados pelo método gravimétrico (AOAC, 2000), enquanto a atividade de água foi determinada com um higrômetro (Aqualab Model Series 3, Decagon Devices Inc., Pullman, EUA). As análises foram realizadas em triplicata.

As propriedades mecânicas de textura das frutas foram efetuadas por meio de teste de penetração com probe cilíndrica de $2 \mathrm{~mm}$ de diâmetro, em analisador de textura TA-XT2, da Stable Micro System (UK), controlado por microcomputador. As amostras foram deformadas $70 \%$ da sua altura original.

Microscopia eletrônica de varredura (MEV) foi utilizada para analisar a estrutura interna das amostras desidratadas por KMFD, KMFD_VD, secagem convectiva e secagem a vácuo. O recobrimento das amostras com ouro foi realizado utilizando um metalizador LEICA (EM SCD500). O microscópio eletrônico de varredura utilizado foi o JEOL JSM 6390LV (Japão), com fonte de elétrons de tungstênio e detector de elétrons secundários e retro-espalhados.

\section{RESULTADOS E DISCUSSÃO}

Os resultados das densidades aparentes das amostras de bananas secas por KMFD, KMFD_VD, CD e VD estão apresentadas na Figura 2. A densidade aparente das amostras secas pelo método convectivo não sofreu alterações significativas durante o processo de secagem, com valores oscilando em torno de $1000 \mathrm{~kg} / \mathrm{m}^{3}$. As maiores reduções na densidade aparente foram de $46 \%$ e $53 \%$, para as amostras submetidas às técnicas de KMFD e KMFD_VD, respectivamente. A redução da densidade aparente das amostras de banana se deve a perda de água e à formação da estrutura porosa durante a secagem. 


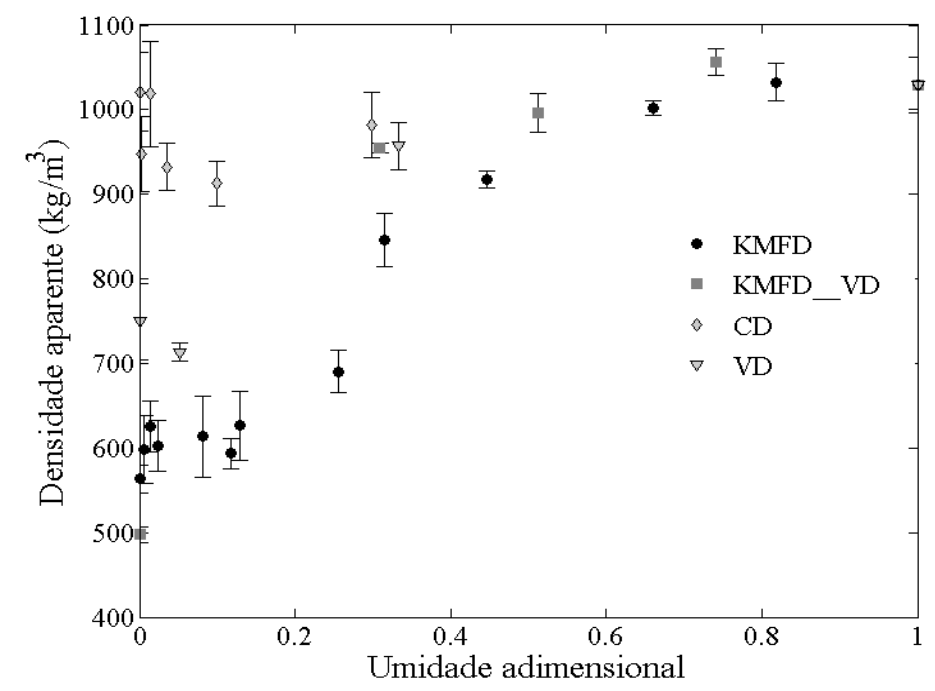

Figura 2 - Densidades aparentes das amostras de bananas secas por conductive multi-flash drying (KMFD), conductive multi-flash drying seguida de um período de secagem a vácuo (KMFD_VD), secagem convectiva $(\mathrm{CD})$ e secagem a vácuo (VD).

Na Figura 3 são apresentados os resultados da evolução da porosidade acessível das amostras (que coincide com a porosidade total da amostra no final da secagem) de banana durante a secagem pelos diferentes processos. A porosidade acessível das amostras submetidas à secagem convectiva foi igual a 56\% ao final do processo, enquanto as amostras de banana desidratadas pela secagem a vácuo apresentaram $70 \%$ de porosidade. As maiores porosidades foram observadas para as amostras secadas por KMFD e KMFD_VD.

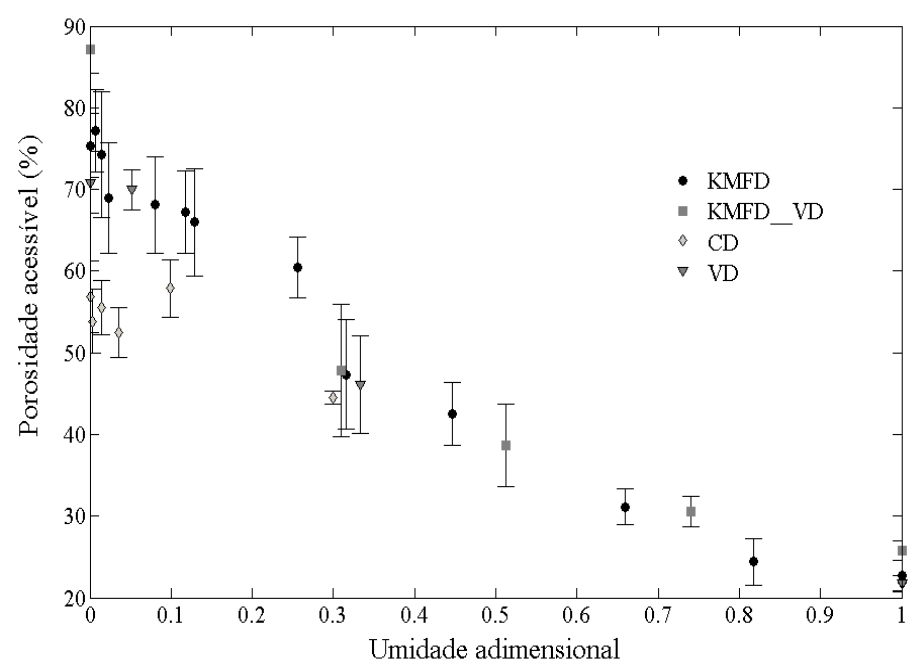

Figura 3 - Porosidades acessíveis das amostras de bananas secas por conductive multi-flash drying (KMFD), conductive multi-flash drying seguida de um período de secagem a vácuo (KMFD_VD), secagem convectiva $(\mathrm{CD})$ e secagem a vácuo (VD). 
Os resultados do encolhimento sofrido pelas amostras de bananas secas pelos diferentes processos estão apresentados na Figura 4, onde se observa que as menores reduções volumétricas foram para as técnicas de KMFD e KMFD_VD. Nessas técnicas a água é removida rapidamente da amostra ao se aplicar o pulso de vácuo (evaporação flash), fazendo com que a matriz sólida não apresente o encolhimento característico do processo de secagem com ar quente. Além disso, a rápida saída do vapor durante a aplicação dos pulsos de vácuo também causa o aumento dos espaços vazios, como pode ser visto nas micrografias (Figura 6). Esse fenômeno contrasta com as baixas taxas de secagem observadas na secagem convectiva, o que facilita a acomodação da matriz celular, causando o encolhimento.

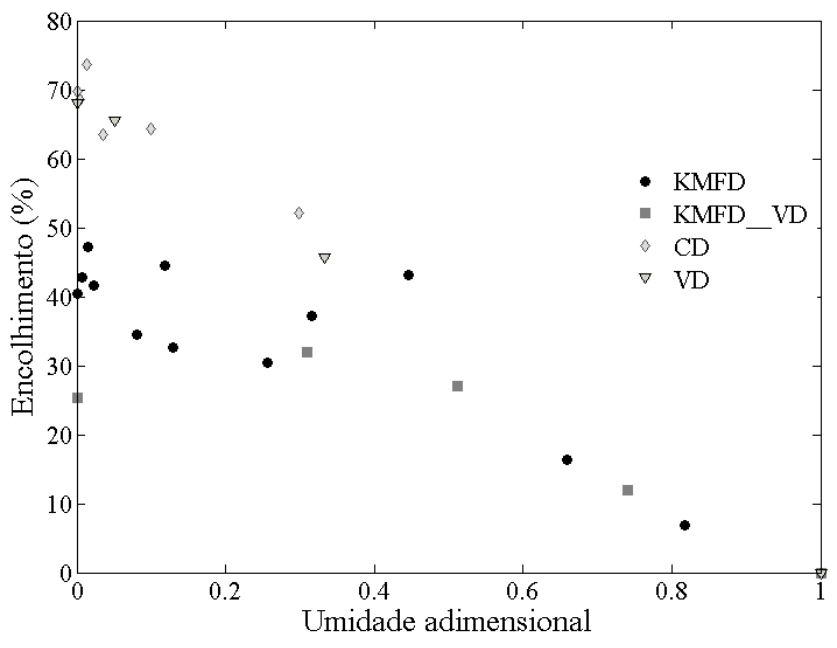

Figura 4 - Encolhimento das amostras de bananas secas por conductive multi-flash drying (KMFD), conductive multi-flash drying seguida de um período de secagem a vácuo (KMFD_VD), secagem convectiva (CD) e secagem a vácuo (VD).

Na Figura 5 estão apresentados os resultados dos ensaios mecânicos de penetração para amostras de bananas desidratadas, onde se observa que o processo de secagem utilizado influenciou significativamente a textura do produto seco. Em materiais com estrutura porosa e quebradiça, a força de penetração oscila muito durante a quebra da parede e desintegração da estrutura. Para as curvas das amostras secas por KMFD, KMFD_VD e VD este comportamento foi observado. 


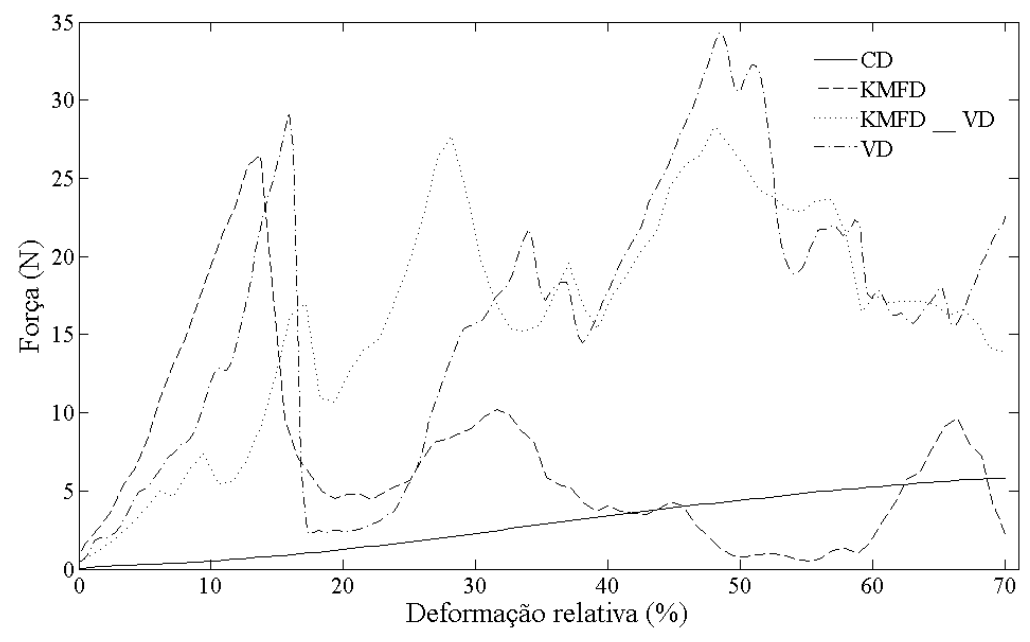

Figura 5 - Testes mecânicos de penetração em amostras de banana desidratadas por conductive multiflash drying (KMFD), conductive multi-flash drying seguida de um período de secagem a vácuo (KMFD_VD), secagem convectiva (CD) e secagem a vácuo (VD).

$\mathrm{Na}$ figura 6 estão apresentadas as micrografias de bananas desidratadas por diferentes técnicas. Analisando as imagens KMFD e KMFD_VD nota-se a formação da matriz porosa resultante da expansão dos vapores contidos na fruta devido à redução da pressão do sistema. O colapso sofrido pelas amostras durante a secagem convectiva e secagem a vácuo pode ser observado nas imagens $\mathrm{CD}$ e VD. Pelas imagens fica claro que a aplicação de sucessivos ciclos de aquecimento-pulso de vácuo favorece a formação da matriz porosa da fruta.

Amostra inicial

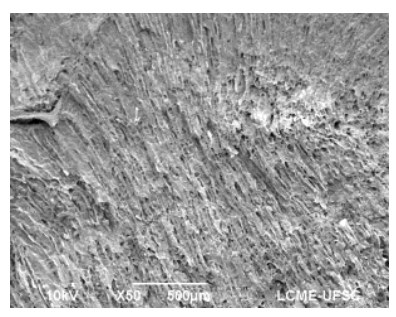

KMFD

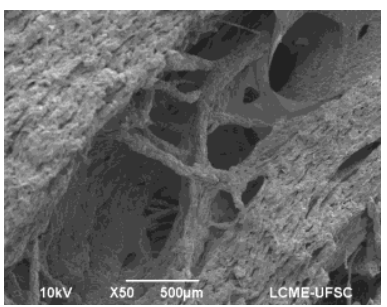

CD

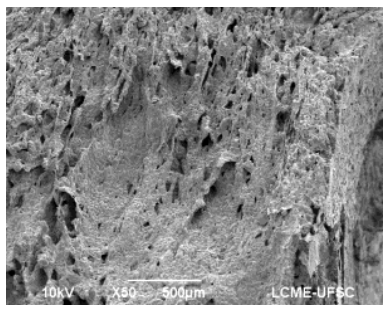

KMFD_VD

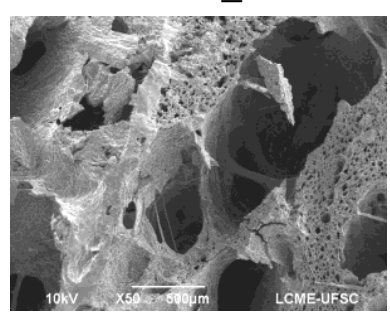

VD

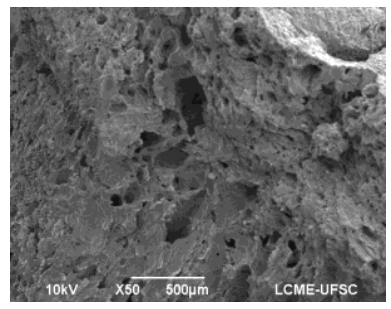

Figura 6 - Microscopias eletrônicas das amostras desidratadas por conductive multi-flash drying (KMFD), conductive multi-flash drying seguida de um período de secagem a vácuo (KMFD_VD), secagem convectiva (CD) e secagem a vácuo (VD). 


\section{CONCLUSÕES}

Os parâmetros densidade aparente, porosidade e encolhimento foram fortemente influenciados pelo processo de secagem. As amostras secas pela técnica de secagem convectiva foram as que apresentaram um maior encolhimento da estrutura e menor porosidade. As amostras submetidas à secagem pelos processos KMFD e KMFD_VD apresentaram alta porosidade e menor encolhimento da estrutura, resultando em produtos crocantes. Esses processos de secagem são de fácil scale-up e podem ser usados como alternativas ao processo de liofilização para a obtenção e frutas e hortaliças crocantes.

\section{REFERÊECIAS}

AOAC. Methods of analysis. 17th ed. Association of official Analytical Chemists.Washington, DC, 2000.

KROKIDA, M. K., KARATHANOS, V. T., MAROULIS, Z. B. Effect of freeze-drying conditions on shrinkage and porosity of dehydrated agricultural products. Journal of Food Engineering, v. 35, p. 369-380, 1998.

LAURINDO, J.B., PORCIUNCULA, B.D.A., ZOTARELLI, M.F. Processo de secagem por sucessivos ciclos de aquecimento-pulso de vácuo (CAPV) para obtenção de alimentos desidratados crocantes. Brazilian Patent, PI 1107173-7, 2011.

LOZANO, J.E., ROTSTEIN, E., URBICAIN, M.J. Total porosity and open-pore porosity in the drying of fruits. Journal of Food Science, v. 45, p. 1403-1407, 1980.

RAMÍREZ, J. R., LAGUNAS, L. M., ORTIZ, A. L., TORRES, S. S. True density and aparent density during the drying process for vegetables and fruits: A review. Journal of Food Science, v. 77 (12), p. 145-154, 2012.

SERENO, A. M., SILVA, M. A., MAYOR, L. Determination of Particle Density and Porosity in Foods and Porous Materials with High Moisture Content.International Journal of Food Properties, v. 10, p. 455-469, 2007.

ZOGZAS, N. P., MAROULIS, Z. B., MARINOS-KOURIS, D. Densities, shrinkage and porosity of some vegetables during air drying. Drying Technology, v. 12(7), p. 1653- 1666, 1994.

ZOTARELLI, M. F., PORCIUNCULA, B. D. A., LAURINDO, J. B. A convective multi-flash drying process for producing dehydrated crispy fruits. Journal of Food Engineering, v. 108, p. 523-531, 2012. 